\title{
The comorbidity burden of patients with cluster headache: a population- based study
}

Shivang Joshi ${ }^{1,2}$, Paul Rizzoli, ${ }^{3,4}$ and Elizabeth Loder ${ }^{3,5^{*}}$

\begin{abstract}
Background: Evidence is limited regarding the comorbidity burden of patients with cluster headache $(\mathrm{CH})$. We aimed to characterize comorbid conditions in a cohort of $\mathrm{CH}$ patients diagnosed by headache experts, using electronic health record information from the Partners Research Patient Data Registry (RPDR).
\end{abstract}

Methods: We identified and reviewed the charts of unique patients diagnosed by headache specialists over an 11-year period, and a set of matched controls. Patients were categorized as having Definite, Unconfirmed or no $\mathrm{CH}$. We calculated the prevalence of and tested for statistically significant differences of selected comorbid conditions in these populations.

Results: An RPDR query identified 170 patients with a free text or ICD diagnosis of cluster headache. 15 records belonging to Partners employees were excluded. 75 patients met diagnostic criteria for $\mathrm{CH}$ (Definite $\mathrm{CH}$ ). 22 had headaches with some features of $\mathrm{CH}$ but the diagnosis was uncertain (Unconfirmed $\mathrm{CH}$ ). In 58 the diagnosis was determined to be inaccurate due to data entry errors. Patients with Definite $\mathrm{CH}$ had an average age of 43.4 years; $80 \%$ were male. The average time from $\mathrm{CH}$ onset to diagnosis was 12.7 years (range 1-51). The average number of yearly emergency department and outpatient visits for the group of Definite $\mathrm{CH}$ patients was 4.5 and 25.4, respectively, compared with 1.1 and 6.9 in controls. Of the 55 examined conditions, four were statistically significantly less common in patients with definite $\mathrm{CH}$ compared with controls (diabetes, musculoskeletal/orthopaedic problems, "other gastrointestinal diagnoses" and skin conditions) and four were statistically significantly more common (smoking, depression, dental disorders and deviated septum).

Conclusions: In this large population-based study, we identified a surprisingly small number of patients who met strict diagnostic criteria for $\mathrm{CH}$. In these patients, however, we identified a distinct pattern of selected comorbidities. The pattern is somewhat but not entirely consistent with that of the "classic" CH patient depicted in the medical literature. CH patients are frequently diagnosed with sinus or dental problems. Many experience substantial delay in receiving a diagnosis. These things may in part explain the high frequency of medical visits in this population. It is difficult to distinguish conditions that are genuinely comorbid with $\mathrm{CH}$ from those that reflect misdiagnoses or medical scrutiny of patients in frequent contact with the healthcare system.

Keywords: Cluster headache, Comorbidity, Diagnostic delay, Misdiagnosis, Healthcare utilization

\footnotetext{
* Correspondence: eloder@partners.org

${ }^{3}$ Harvard Medical School, Boston, USA

${ }^{5}$ Division of Headache, Department of Neurology, Brigham and Women's

Faulkner Hospitals, Boston, MA 02130, USA

Full list of author information is available at the end of the article
} 


\section{Background}

Cluster headache is a relatively uncommon primary headache disorder that is one of the trigeminal autonomic cephalgias. Its lifetime prevalence is estimated to be 124 per 100,000 persons with a one-year prevalence of 53 per million [1, 2]. Cluster headache is considered to be among the most severe forms of pain. Patients with cluster headache experience substantial decrements in quality of life and have many other health-related burdens [3].

Comorbidity is defined as the presence of separate illnesses in the same patient at a frequency greater than would be expected by chance [3,4]. Clinical experience and previous research, summarized in Table 1 , suggest that $\mathrm{CH}$ patients have a higher prevalence than the general population of a number of comorbidities, including such things as coronary artery disease, head trauma, peptic ulcer disease, and alcohol and tobacco use. However, previous studies were small, did not always include representative samples of patients with $\mathrm{CH}$, and had other methodological limitations. For these reasons, using information from a specialty headache clinic located in a large academic medical center, we aimed to study the comorbidity burden of patients with $\mathrm{CH}$.

\section{Methods}

The Partners Healthcare Institutional Review Board approved the study. We used the Partners Research Patient Data Registry (RPDR) to identify unique patients with $\mathrm{CH}$. The RPDR is a relational database containing clinical and administrative information on millions of patients seen within the Partners Healthcare System [5]. Partners Health Care is a not-for-profit, integrated health care system in Boston, Massachusetts that provides care for roughly $50 \%$ of the population in the Boston metropolitan area. Partners Health Care includes community and specialty hospitals, a managed care organization, a physician network, community health centers, home care and other health related services. During the period of this study, Partners Healthcare used a proprietary electronic medical record system known as the Longitudinal Medical Record (LMR). Physicians could directly dictate or enter typed information into the medical record. Physicians recorded International Classification of Diseases, version 9 (ICD-9) diagnoses on a billing sheet by circling or checking a list of common diagnoses. Physicians could also hand-write an ICD-9 code on this sheet. This diagnostic information was entered into the electronic billing system by billing assistants and subsequently imported into RPDR.

We searched for patients who had received a diagnosis of cluster headache during a 10 year period between 2002 and 2012 from one of nine headache specialists known to be practicing within the Partners system during this period. The search was limited to patients diagnosed by headache specialists because the accuracy of cluster headache diagnoses by non-specialists is known to be low [6].

We identified medical record numbers of unique patients seen between $1 / 1 / 2002$ and 12/31/2012 who had received a diagnosis of cluster headache. Patients diagnosed with cluster headache were identified in two ways. First, we searched for patients for whom an International Classification of Diseases (ICD) code for cluster headache had ever been recorded. For example, the ICD-9 code for episodic cluster headache is 339.01. Second, we searched for charts in which relevant terms ("Episodic Cluster Headache", "Chronic Cluster Headache" or "Cluster Headache") appeared in the free text problem list, as a diagnosis not associated with an ICD code, or elsewhere in the medical record. Our final list consisted of patients who met either of these criteria, with duplicate records removed. For reasons of privacy, we did not include records belonging to patients who were employees of Partners Healthcare. Charts that appeared to be inaccurately coded were also removed. For example, patients who had received a diagnostic code for $\mathrm{CH}$ but who were described in the notes as having migraine were eliminated based on the assumption that a data entry error had occurred.

Two researchers independently examined each medical record and attempted to validate the diagnosis of cluster headache by locating information required to make a diagnosis of cluster headache. Information from each eligible patient's record indicating the physician considered him or her to have $\mathrm{CH}$ was considered the gold standard for the presence of $\mathrm{CH}$. Patients were categorized as having "Definite cluster headache" if the medical record contained sufficient information to make a diagnosis of cluster headache according to ICHD-2 criteria [1]. We did not distinguish between episodic and chronic forms of the disorder. Patients were categorized as having "Unconfirmed cluster headache" if information in the medical record indicated they met some criteria for cluster headache, but information was insufficient to make a Definite diagnosis according to ICHD criteria.

Using structured RPDR query methods, we identified two age and sex matched controls without cluster headache for each patient in the group of Definite $\mathrm{CH}$ patients. RPDR allows researchers to define criteria for the selection of healthy controls, and to choose the number of controls for each case patient. Using an algorithm, patients matching these criteria, but without the disease in question, are randomly selected and their medical record numbers are returned to the researcher, who is then able to retrieve the full medical record.

The medical records of patients with Definite and Unconfirmed cluster headache, as well as controls, were then 
Table 1 Selected previous studies of comorbidity in cluster headache

\begin{tabular}{|c|c|c|c|c|}
\hline Author, Year & Population, setting & Design & Comorbidities & Comments \\
\hline Ferrari, 2013 [15] & $\begin{array}{l}200 \text { consecutive male } \\
\text { and female } \mathrm{CH} \text { patients } \\
\text { from Italian headache } \\
\text { clinic }\end{array}$ & $\begin{array}{l}\text { Cross-sectional survey } \\
\text { study }\end{array}$ & $\begin{array}{l}60 \% \text { were current, } 21 \% \text { former, } \\
19 \% \text { never smokers. }\end{array}$ & $\begin{array}{l}\text { No change in headache noted in } \\
\text { those who had stopped smoking. }\end{array}$ \\
\hline Kudrow, 1976 [16] & $\begin{array}{l}140 \text { male and female } \mathrm{CH} \\
\text { patients vs. controls from } \\
\text { a California headache } \\
\text { clinic and healthy } \\
\text { outpatients }\end{array}$ & $\begin{array}{l}\text { Cross-sectional chart } \\
\text { review }\end{array}$ & $\begin{array}{l}\text { Men with CH had a statistically } \\
\text { significantly higher prevalence } \\
\text { of peptic ulcer disease compared } \\
\text { with controls. No increased risk } \\
\text { of coronary artery disease was } \\
\text { demonstrated. }\end{array}$ & \\
\hline
\end{tabular}

Lambru, 2010 [17] 200 male CH patients and 200 migraine controls from Italian headache clinic

Liang, 2013 [18]

673 male and female $\mathrm{CH}$ patients from a Taiwanese National Health Database

Pietrini, 2005 [19]

60 consecutive male and female $\mathrm{CH}$ patients seen at an Italian headache center

Robbins, 2012 [20] 49 consecutive male and female $\mathrm{CH}$ patients seen in a New York headache clinic over a 3.5 year period

Rossi, 2012 [21]

210 consecutive male and female $\mathrm{CH}$ patients from two Italian headache centers

Rozen, 2012 [22]

1134 US male and female $\mathrm{CH}$ patients responding to an internet survey

Van Alboom, 2009 [9] 85 male and female CH patients from 4 Belgian neurology clinics
Cross-sectional chart review

Prevalence of traumatic head $23 \%$ in controls (OR 2.0 (95\% Cl 1.3 to 4.9). Prevalence of alcohol use was $74.5 \%$ and cigarette smoking $75 \%$ in those with $\mathrm{CH}$.

Retrospective cohort study with 2.5 year median follow-up duration

Cross-sectional, based on study examination

Cross-sectional chart review

$3.6 \%$ developed depression over study period. Adjusted HR 5.6\% vs. controls but not different from those with migraine; number of bouts/year of $\mathrm{CH}$ a risk factor for depression.

$35 \%$ had hypertension, defined as blood pressure $\geq 140 / 90$ on average of 3 blood pressure readings. 10 ) was $6.3 \%$ in episodic $\mathrm{CH}, 11.8 \%$ in chronic $\mathrm{CH}$; Anxiety (GAD-7 $\geq 10$ ) prevalence was $15.6 \%$ in episodic $\mathrm{CH}$ and $11.8 \%$ in chronic $\mathrm{CH}$. Prevalence of hypertension was $14 \%$, current or former cigarette smoking was $65.3 \%$ and GERD was $8 \%$.

Cross-sectional interview $92.5 \%$ of male $\mathrm{CH}$ patients and and anonymous survey $\quad 85.4 \%$ of female $\mathrm{CH}$ patients data reported current or past use of tobacco, statistically significantly higher than prevalence in general population.

Cross-sectional survey (internet)

Prevalence of depression was $24 \%$ suicidal ideation was reported by $55 \%$, sleep apnea by $14 \%$, restless leg syndrome by $11 \%$, asthma by $9 \% .73 \%$ were current or former smokers; $51 \%$ had been smoking at the time $\mathrm{CH}$ began. $65 \%$ used alcohol but only $3 \%$ reported a history of alcohol abuse. The prevalence of coronary problems was low: $1 \%$ had a history of myocardial infarction, $0.3 \%$ bypass surgery and $1 \%$ stent placement. Peptic ulcer disease was reported by $5 \%$, diabetes by $3 \%$ and epilepsy by $1 \%$.

Cross-sectional chart review $45 \%$ had been diagnosed with migraine, $23 \%$ with sinusitis, injuries $38.5 \%$ in those with $\mathrm{CH}$ vs.

Prevalence of depression (PHQ $\geq$

Only males included in this study.

Study limited to patients diagnosed by neurologist and prescribed standard $\mathrm{CH}$ drugs; excluding those with previous psychiatric diagnoses (104 of original 777; 13\%).

The authors concluded that the prevalence of hypertension in this group was within expected range given age and sex.

Self reported data on substance use.

Unlikely to be a representative sample of patients with $\mathrm{CH}$ due to self-selected nature of participants. Diagnosis not medically verified. Respondents compared with the US population in general rather than matched controls. Data should be interpreted cautiously.

Average diagnostic delay was tooth/jaw problems 23\%, trigeminal neuralgia $16 \%$. 
Table 1 Selected previous studies of comorbidity in cluster headache (Continued)

\begin{tabular}{|c|c|c|c|}
\hline $\begin{array}{l}\text { Voiticovschi -losob, } \\
2014 \text { [23] }\end{array}$ & $\begin{array}{l}144 \text { male and female } \\
\text { Italian and Eastern } \\
\text { European patients with } \\
\text { episodic cluster } \\
\text { headache }\end{array}$ & $\begin{array}{l}\text { Cross-sectional } \\
\text { (diagnostic interview } \\
\text { and survey) }\end{array}$ & $\begin{array}{l}16 \% \text { of } \mathrm{CH} \text { patients had previously } \\
\text { been diagnosed with sinusitis; } 4.2 \% \\
\text { with dental disorders. }\end{array}$ \\
\hline Xie, 2013 [24] & $\begin{array}{l}26 \text { male and female } \mathrm{CH} \\
\text { patients identified by } \\
\text { survey in tertiary Chinese } \\
\text { headache clinic }\end{array}$ & $\begin{array}{l}\text { Cross-sectional } \\
\text { (diagnostic interview) }\end{array}$ & $\begin{array}{l}\text { 14/26 (54\%) were current smokers, } \\
19.2 \% \text { former and } 26.9 \% \\
\text { nonsmokers. }\end{array}$ \\
\hline $\begin{array}{l}\text { Zidverc-Trajkovic, } \\
2011 \text { [8] }\end{array}$ & $\begin{array}{l}130 \text { consecutive male } \\
\text { and female } \mathrm{CH} \text { patients } \\
\text { and } 982 \text { with migraines } \\
\text { in a specialty headache } \\
\text { clinic }\end{array}$ & $\begin{array}{l}\text { Cross-sectional chart } \\
\text { review }\end{array}$ & $\begin{array}{l}\text { Prevalence of anxiety or depression } \\
\text { in } \mathrm{CH} \text { was } 4.6 \% \text {, chronic sinusitis } \\
3.6 \% \text { diabetes mellitus } 3.8 \% \text {. }\end{array}$ \\
\hline
\end{tabular}

Abbreviations: $C H$ cluster headache, GAD-7 generalized anxiety disorder 7-item scale, GERD gastroesophageal reflux disease, $H R$ hazard ratio, ICHD International classification of headache disorders, $O R$ odds ratio, $P H Q-9$ patient health questionnaire 9-item scale

hand-searched by one author (SJ), who abstracted information on headache characteristics, age at onset and age at diagnosis of $\mathrm{CH}$, as well as relevant comorbidities using a standardized data abstraction form. A second author (EL) reviewed a subset of medical records to verify the accuracy of data abstraction. Differences were resolved through consensus. We recorded all comorbid disorders identified in patient records, resulting in the list of 56 conditions listed in Table 2. The same methods were used to search for comorbidities in the charts of $\mathrm{CH}$ patients and those of controls, namely one authors (SJ) used the RPDR Data Query tool to search for diagnoses of these 56 conditions. The Query tool allows researchers to use the Notes Search function, which searches in all ambulatory notes and clinical reports for a particular patient for specific diagnoses or terms. A diagnosis of alcohol abuse was inferred if the patient was recorded as ever participating in an alcohol abuse program or if listed as a medical condition by the physician on a problem list or appeared as a diagnosis in the medical record. Similarly, patients were categorized as cigarette, cigar or other substance users if the patient was recorded as ever using those substances.

We also performed queries in RPDR to determine demographic characteristics and other information such as the average yearly number of emergency and outpatient visits for the entire $\mathrm{CH}$ group (Definite and Unconfirmed), the age and sex-matched control group, and the entire population of patients in RPDR, the latter to help put results for the $\mathrm{CH}$ population in context.

\section{Analysis}

All data were analyzed using SPSS statistical software (IBM Corp. Released 2012. IBM SPSS Statistics for Windows, Version 21.0. Armonk, NY: IBM Corp.) We calculated Pearson's chi-square statistics for differences in proportions and considered a $p$ value $<0.05$ to be significant. We also distinguish between comparisons for which the $p$ value is $<0.01$ and $<0.001$, as a way of allowing readers to account for multiple comparisons.

\section{Results}

Figure 1 shows the flow of patients through the study. The initial search from $12 / 1 / 2002$ to $6 / 30 / 2012$ among nine headache specialists identified a total of 170 patients who had received an ICD-9 diagnosis of $\mathrm{CH}$ and/or had a free text diagnosis of $\mathrm{CH}$ recorded by the physician or included in the problem list. 116 of these patients were identified by ICD-9 codes alone. After removal of patients who were employees of the Partners Healthcare system, 155 patients remained. Following exclusion of 58 inaccurately coded charts, a total of 97 patients remained in the final analysis. After chart review and data abstraction by 2 experts, 75 patients were determined to clearly meet criteria for cluster headache (Definite $\mathrm{CH}$ ). For these 75 patients, RPDR identified 152 age and sex-matched controls. 22 patients had headaches with some features of $\mathrm{CH}$ but the diagnosis could not be confirmed from information contained in the medical record (Unconfirmed $\mathrm{CH}$ ). The main reason that patients were included in the Unconfirmed rather than the Definite $\mathrm{CH}$ group was duration of headache over $3 \mathrm{~h}$.

Figure 2 illustrates the distribution of patients with Definite $\mathrm{CH}$ by self-reported age at onset of $\mathrm{CH}$ in comparison with age at the time of $\mathrm{CH}$ diagnosis. The average time from first appearance of symptoms to diagnosis was 12.7 years (range 1 to 51). Figure 3 shows the average number of yearly inpatient, clinic and emergency department visits for patients with Definite $\mathrm{CH}$, age and sex-matched controls and (to provide context) the entire population of patients in the RPDR. $\mathrm{CH}$ patients had a higher average number of emergency department and 
Table 2 Demographic characteristics and prevalence of comorbid conditions in patients with definite and unconfirmed $\mathrm{CH}$ and controls

\begin{tabular}{|c|c|c|c|c|}
\hline & $\begin{array}{l}\text { Definite } \\
n=75\end{array}$ & $\begin{array}{l}\text { Control } \\
n=152\end{array}$ & $\begin{array}{l}\text { Unconfirmed } \\
n=22\end{array}$ & \\
\hline Mean age in years (range) & $\begin{array}{l}43.4 \\
(20-74)\end{array}$ & & $\begin{array}{l}44 \\
(20-74)\end{array}$ & \\
\hline Proportion of males & $80 \%$ & $80 \%$ & $45 \%$ & \\
\hline Comorbidity & $\%$ & $\%$ & $\%$ & $\begin{array}{l}p \text { value definite } v \text { controls } \\
\text { Pearson chi-square }\end{array}$ \\
\hline Attention deficit disorder & 4 & 2 & 0 & 0.4 \\
\hline Anxiety & 7 & 8 & 18 & 0.7 \\
\hline Arthritis/Rheumatologic condition & 15 & 11 & 14 & 0.4 \\
\hline Asthma & 7 & 7 & 0 & 1 \\
\hline Back pain/Spine condition & 17 & 14 & 14 & 0.56 \\
\hline Celiac disease & 1 & 0 & 0 & 0.32 \\
\hline Cerebrovascular disease & 1 & 1 & 0 & 1 \\
\hline Cigar smoking & 4 & 1 & 0 & 0.17 \\
\hline Cigarette smoking & 64 & 32 & 31 & $0.00077^{* * *}$ \\
\hline Congenital disease & 0 & 3 & 0 & 0.08 \\
\hline COPD & 1 & 1 & 0 & 1 \\
\hline Cardiovascular disease & 15 & 16 & 36 & 0.85 \\
\hline Dental/TMJ & 4 & 0 & 5 & $0.04^{*}$ \\
\hline Depression & 17 & 7 & 23 & $0.03^{*}$ \\
\hline Deviated septum & 7 & 1 & 5 & $0.03^{*}$ \\
\hline Diabetes & 0 & 9 & 5 & $0.002^{* *}$ \\
\hline Divorce & 13 & 7 & 14 & 0.16 \\
\hline Endocrine & 8 & 3 & 9 & 0.12 \\
\hline Alcohol abuse & 17 & 8 & 5 & 0.054 \\
\hline Alcohol moderate & 1 & 3 & 0 & 0.31 \\
\hline Fibromyalgia & 5 & 1 & 0 & 0.1 \\
\hline GERD & 8 & 10 & 9 & 0.62 \\
\hline Gl procedures & 7 & 8 & 0 & 0.79 \\
\hline Glaucoma/Ocular & 3 & 3 & 5 & 1 \\
\hline Head trauma & 5 & 1 & 9 & 0.1 \\
\hline Hematologic & 3 & 7 & 14 & 0.19 \\
\hline Hyperlipidemia & 25 & 25 & 32 & 1 \\
\hline Hypertension & 15 & 22 & 18 & 0.2 \\
\hline Irritable bowel syndrome & 4 & 1 & 14 & 0.17 \\
\hline Infectious & 5 & 4 & 9 & 0.73 \\
\hline Malignancy & 9 & 16 & 14 & 0.13 \\
\hline Marijuana & 8 & 4 & 9 & 0.23 \\
\hline Musculoskeletal/Ortho & 7 & 16 & 5 & $0.046^{*}$ \\
\hline Nephrolithiasis & 7 & 2 & 0 & 0.08 \\
\hline Ob/Gyn & 4 & 5 & 0 & 0.73 \\
\hline Obesity & 3 & 7 & 9 & 0.19 \\
\hline Other Gl & 9 & 24 & 5 & $0.004^{* *}$ \\
\hline Other Headache & 5 & 3 & 5 & 0.47 \\
\hline Other Neurologic & 4 & 7 & 9 & 0.35 \\
\hline
\end{tabular}


Table 2 Demographic characteristics and prevalence of comorbid conditions in patients with definite and unconfirmed $\mathrm{CH}$ and controls (Continued)

\begin{tabular}{|c|c|c|c|c|}
\hline Other Pain, e.g. fibromyalgia & 3 & 5 & 0 & 0.47 \\
\hline Other Psychiatric disorder & 7 & 5 & 14 & 0.55 \\
\hline Other sleep & 3 & 5 & 5 & 0.47 \\
\hline Other Substance abuse & 3 & 4 & 9 & 0.7 \\
\hline Peptic ulcer disease & 4 & 1 & 9 & 0.17 \\
\hline Renal & 1 & 3 & 0 & 0.31 \\
\hline Restless legs & 0 & 0 & 0 & 1 \\
\hline Seizure disorder & 5 & 5 & 5 & 1 \\
\hline Sinus problems & 5 & 8 & 9 & 0.39 \\
\hline Skin conditions & 4 & 19 & 5 & $0.0008^{* * *}$ \\
\hline Sleep apnea & 9 & 5 & 5 & 0.27 \\
\hline Suicide attempt & 0 & 1 & 0 & 0.32 \\
\hline Tendinitis & 7 & 3 & 5 & 0.19 \\
\hline Trigeminal neuralgia & 0 & 0 & 0 & 1 \\
\hline Urologic & 5 & 10 & 5 & 0.18 \\
\hline Vascular malformation & 1 & 0 & 0 & 0.32 \\
\hline Violent trauma & 0 & 2 & 0 & 0.16 \\
\hline
\end{tabular}

Abbreviations: $A D D$ attention deficit disorder, COPD chronic obstructive pulmonary disease, Gl gastrointestinal, Ob/gyn obstetrical or gynecological diagnoses ${ }^{*}$ significant at $<0.05,{ }^{* *}$ significant at $<0.01,{ }^{* *}$ significant at $<0.001$

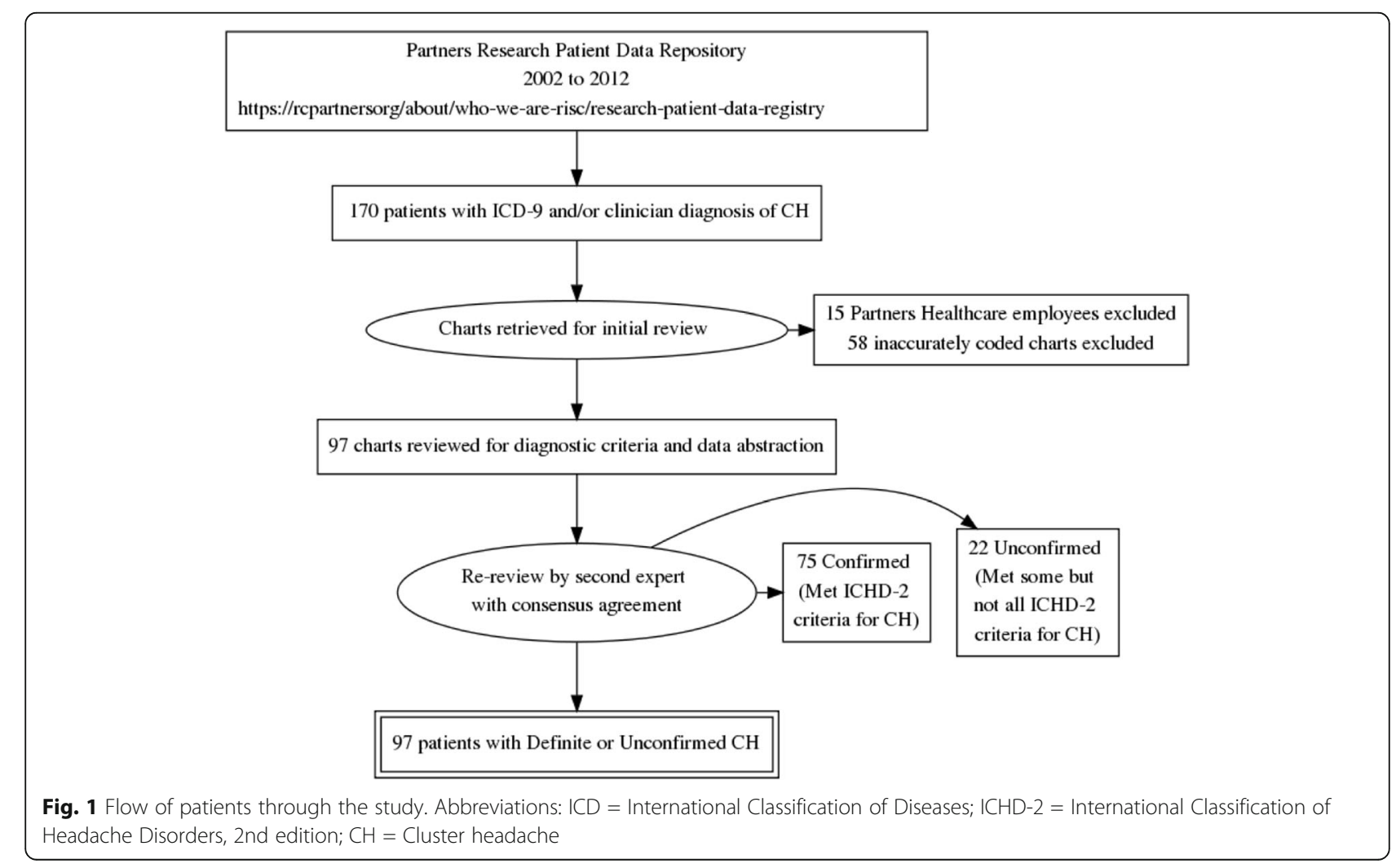




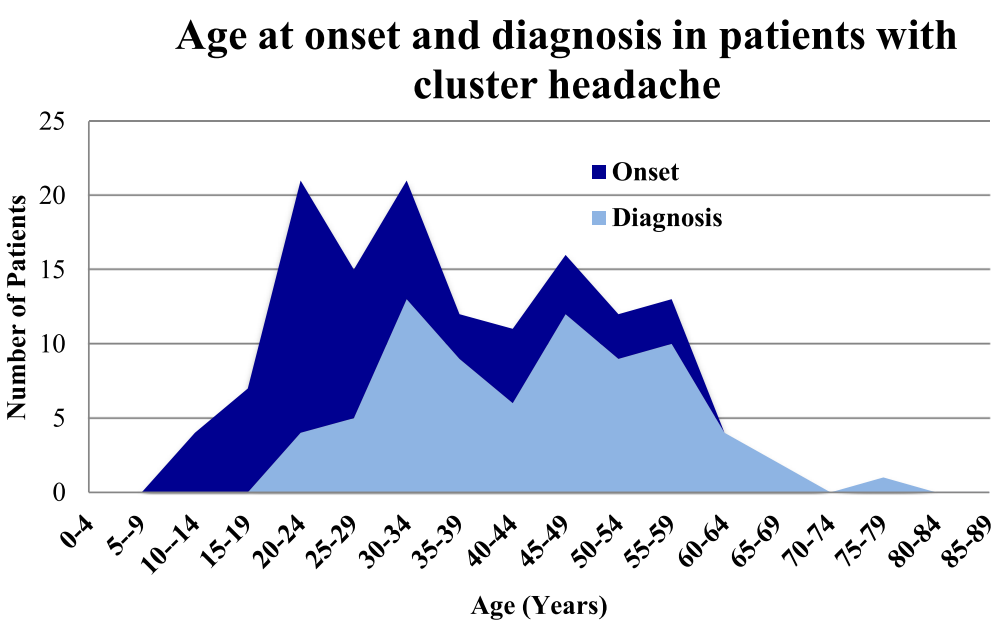

Fig. 2 Age at onset and diagnosis in 75 patients with definite cluster headache

clinic visits compared to either controls or the entire RPDR population.

Table 2 shows the demographic characteristics and comorbidity burden of patients with Definite $\mathrm{CH}$ compared to those with Unconfirmed $\mathrm{CH}$ and matched controls. The average age of the Definite $\mathrm{CH}$ group was similar to that of the Unconfirmed group (43.4 $\mathrm{v} 44$ years), but the sex ratio was notably different. 60/75 (80\%) of patients with Definite $\mathrm{CH}$ were men, compared to just 10/22 (45\%) with Unconfirmed $\mathrm{CH}$.

The prevalence of eight of the 56 studied comorbidities was statistically significantly different in patients with Definite $\mathrm{CH}$ compared with age and sex-matched controls. Specifically, patients with Definite $\mathrm{CH}$ had a higher prevalence of diagnoses of cigarette smoking, deviated septum, dental/TMJ problems and depression than controls, and a lower prevalence of skin problems, diabetes, musculoskeletal complaints or "other gastrointestinal" problems.

\section{Discussion}

In this large population-based study, we identified a surprisingly small number of patients who met strict criteria for $\mathrm{CH}$, but a larger number who were considered by expert clinicians to have a $\mathrm{CH}$ disorder. This suggests that the sensitivity of existing diagnostic criteria in clinical practice is low. However, in patients diagnosed by expert headache clinicians with $\mathrm{CH}$ over an 11 year period, we did identify a distinct pattern of selected comorbidities compared with age and sex-matched controls. The pattern of patient characteristics and comorbidities that emerged from our study is somewhat but not entirely consistent with that of the "classic" $\mathrm{CH}$ patient depicted in the medical literature. Our study does not suggest that $\mathrm{CH}$ patients are more likely to have cardiovascular disease, or to use or abuse alcohol in comparison with non- $\mathrm{CH}$ controls. This is not necessarily inconsistent with prior studies, which often looked at alcohol consumption and use;

\section{Healthcare visits and admissions}

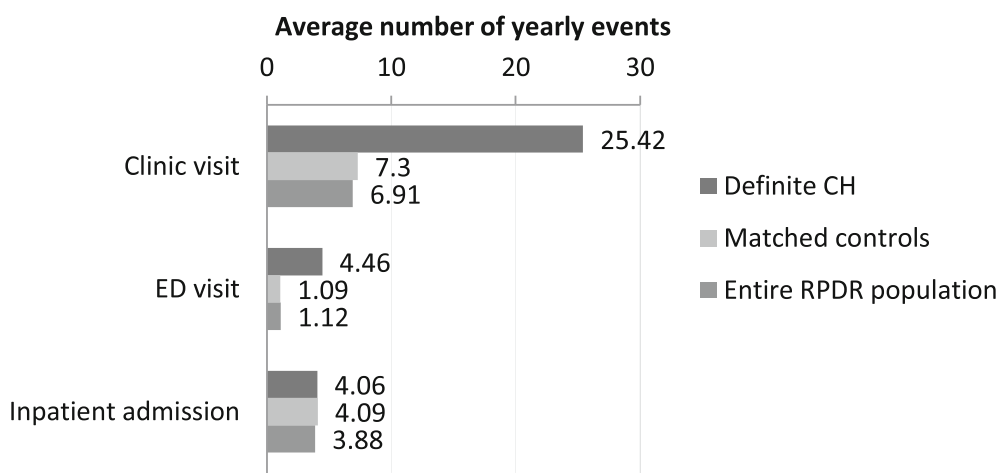

Fig. 3 The average number of yearly emergency department (ED) and clinic visits was higher for CH patients compared with the entire RPDR population or controls 
even if $\mathrm{CH}$ patients are more likely to drink alcohol than non- $\mathrm{CH}$ sufferers, it is not clear they are more likely to have alcohol abuse. In our study $\mathrm{CH}$ patients were less likely to have diabetes than controls. The majority of patients diagnosed with cluster headache in this population were men and they were more likely to have received diagnoses of depression, and of deviated septum or dental/temporomandibular joint problems, perhaps reflecting previous inaccurate diagnoses of the cause of their unilateral head pain rather than true comorbidities.

In fact it is difficult to distinguish between conditions that are comorbid with $\mathrm{CH}$ and those that represent misdiagnoses of the disorder or selection bias due to the high number of healthcare visits that $\mathrm{CH}$ patients have. This increases the likelihood that latent medical problems will be diagnosed during evaluation and testing, a phenomenon known as "Berkson's bias" [7]. CH patients are frequently diagnosed with sinus or dental problems, and many experience substantial delay in receiving a diagnosis [8-10]. These things may in part explain the high frequency of medical visits in this population. Nonetheless, caution should be used in interpreting our results, since it is not possible to distinguish conditions that are genuinely comorbid with $\mathrm{CH}$ from those that reflect misdiagnoses or result from increased medical scrutiny of patients in frequent contact with the healthcare system. Several of the comorbidities we identified, particularly sinus or dental problems, are very likely to reflect misdiagnoses of $\mathrm{CH}$ rather than true comorbid conditions.

Although patients with Definite $\mathrm{CH}$ were statistically significantly more likely to have a history of cigarette smoking than controls, this was not true for cardiovascular conditions or alcohol use disorders. The prevalence of diabetes was significantly lower in patients with $\mathrm{CH}$ than in matched controls. This raises the question of whether diabetes might protect against the development or expression of $\mathrm{CH}$, something that could be explored in future studies. Notably, $\mathrm{CH}$ patients had a statistically significantly elevated prevalence of diagnoses of deviated septum and dental or temporomandibular problems, which might represent previous inaccurate diagnoses of their unilateral head pain.

Our data are consistent with previous findings of a long delay between the appearance of $\mathrm{CH}$ symptoms and receipt of a correct diagnosis [11, 12]. Our findings also quantify the increased use of healthcare among patients with $\mathrm{CH}$. A previous study from Denmark found that $43.5 \%$ of $\mathrm{CH}$ patients had consulted a general practitioner during the previous year, compared with $9.2 \%$ of the general public. $43.5 \%$ had consulted a specialist, compared with $3.3 \%$ of the general public [3] In our study, $\mathrm{CH}$ patients had roughly 3 times the number of outpatient and 4 times the number of emergency department visits in an average year, indicating a high medical burden. It is possible that some of these visits represent attempts to obtain an accurate diagnosis or effective treatment for $\mathrm{CH}$. This suggests that healthcare payers could realize important costs savings through improved recognition and treatment of $\mathrm{CH}$.

The majority of patients in the Unconfirmed $\mathrm{CH}$ group were female. This is in contrast to the predominance of males in the Definite $\mathrm{CH}$ group. In this subgroup a major reason patients did not meet criteria for Definite $\mathrm{CH}$ was duration of $\mathrm{CH}$ longer than the three-hour maximum allowed by diagnostic criteria. A longer duration of attacks in women compared with men who have $\mathrm{CH}$ was not noted in a previous study that examined sex-specific attack differences [13]. Thus, it is possible, even likely that many patients in the Unconfirmed group did not have cluster headache but instead had migraine with prominent autonomic symptoms. The sex distribution would support this hypothesis. On the other hand, the clinicians making the diagnosis of $\mathrm{CH}$ were experienced headache experts, who presumably considered this possibility but still felt that the headaches were more likely to be $\mathrm{CH}$.

It is interesting to note that the pattern of comorbidities and diagnostic delay was very similar in the Definite and Unconfirmed groups. These similarities support the view that these groups suffer from a single disorder. The ICHD criteria represent a compromise between the clinical need for sensitive criteria and the research need for specificity. It is thus not surprising that the sensitivity of the criteria is somewhat lower than ideal for clinical purposes. Clinicians should bear in mind that in clinical practice, strict adherence to ICHD criteria would result in missing patients who likely do have $\mathrm{CH}$ and would benefit from treatment. This is especially true for women with the disorder.

\section{Conclusions}

Our findings provide high quality information in a representative sample of patients with expert-confirmed and carefully validated cluster headache diagnoses seen in a large academic medical system over the course of a decade. Strengths of this study include careful validation of $\mathrm{CH}$ diagnosis, an electronic medical record with semi-standardized data entry that allowed thorough characterization of the natural history and clinical course of patients, as well as high quality, complete information on comorbidities in our patient population and age and sex matched controls. Our study also has a number of limitations. We performed multiple comparisons, which increases the chance that some findings are false positives. Because of this our findings should be viewed as descriptive and hypothesis-generating. In most cases, comorbidities were diagnosed clinically rather than using structured diagnostic criteria. We used the second version of the 
ICHD criteria for this study rather than the current 3-beta version [14]. However, the only change to the diagnostic criteria in the latest version was the addition of a "sensation of ear fullness" or "forehead and facial flushing" to the list of ipsilateral autonomic symptoms or signs. These symptoms were not mentioned in any of the clinical notes we reviewed, so these minor changes are unlikely to have any material effect on our findings or conclusions.

\section{Abbreviations}

$\mathrm{CH}$ : Cluster headache; EHR: Electronic health record; RPDR: Research patient data registry

\section{Acknowledgements}

The authors thank Shawn Murphy and Henry Chueh and the Partners Health Care Research Patient Data Registry group for facilitating use of the database. This work was conducted with support from Harvard Catalyst | The Harvard Clinical and Translational Science Center (National Center for Research Resources and the National Center for Advancing Translational Sciences, National Institutes of Health Award 8UL1TR000170-05 and financial contributions from Harvard University and its affiliated academic health care centers). The content is solely the responsibility of the authors and does not necessarily represent the official views of Harvard Catalyst, Harvard University and its affiliated academic health care centers, or the National Institutes of Health.

\section{Funding}

No funding was received for this study.

\section{Availability of data and materials}

No additional data are available - all aggregate data are reported in this manuscript.

\section{Authors' contributions}

SJ contributed to design and conception of the work, acquisition and interpretation of the data, drafting the work, and gave final approval of the work. PR contributed to design and conception of the work, revising it critically for important intellectual content and gave final approval of the work. EL contributed to design and conception of the work, acquisition and interpretation of the data, revision for important intellectual content and gave final approval of the work. All authors agree to be accountable for all aspects of the work in ensuring that questions related to the accuracy or integrity of any part of the work are appropriately investigated and resolved. All authors read and approved the final manuscript.

\section{Ethics approval and consent to participate}

This study was approved by the Partners Institutional Review Board.

\section{Consent for publication}

Not applicable.

\section{Competing interests}

The authors declare that they have no competing interests.

\section{Publisher's Note}

Springer Nature remains neutral with regard to jurisdictional claims in published maps and institutional affiliations.

\section{Author details}

'Clinical Pharmacy Practice, MCPHS University College of Pharmacy, Worcester, USA. ${ }^{2}$ Community Neuroscience Services, Westborough, MA 01581, USA. ${ }^{3}$ Harvard Medical School, Boston, USA. ${ }^{4}$ Graham Headache Center, Brigham and Women's Faulkner Hospitals, Boston, MA 02130, USA. ${ }^{5}$ Division of Headache, Department of Neurology, Brigham and Women's Faulkner Hospitals, Boston, MA 02130, USA.
Received: 5 June 2017 Accepted: 13 July 2017

Published online: 24 July 2017

\section{References}

1. Headache Classification Subcommittee of the International Headache Society (2004) The international classification of headache disorders: 2nd edition. Cephalalgia 24(Suppl 1):9-160

2. Fischera M, Marziniak M, Gralow I, Evers S (2008) The incidence and prevalence of cluster headache: a meta-analysis of population-based studies. Cephalalgia 28(6):614-618

3. Jensen RM, Lyngberg A, Jensen RH (2007) Burden of cluster headache. Cephalalgia 27(6):535-541

4. Bonavita V, De Simone R (2008) Towards a definition of comorbidity in the light of clinical complexity. Neurol Sci 29(Suppl 1):S99-102

5. Nalichowski R, Keogh D, Chueh HC, Murphy SN (2006) Calculating the benefits of a Research Patient Data Repository. AMIA Annu Symp Proc: 2006:1044

6. Voiticovschi-losob C, Allena M, De Cillis I, Nappi G, Sjaastad O, Antonaci F (2014) Diagnostic and therapeutic errors in cluster headache: a hospitalbased study. J Headache Pain 15(1):56

7. Berkson J (1946) Limitations of the application of fourfold table analysis to hospital data. Biometrics 2(3):47-53

8. Zidverc-Trajkovic JJ, Pekmezovic TD, Sundic AL, Radojicic AP, Sternic NM (2011) Comorbidities in cluster headache and migraine. Acta Neurol Belg 111(1):50-55

9. Van Alboom E, Louis P, Van Zandijcke M, Crevits L, Vakaet A, Paemeleire K (2009) Diagnostic and therapeutic trajectory of cluster headache patients in Flanders. Acta Neurol Belg 109(1):10-17

10. Gross SG (2006) Dental presentations of cluster headaches. Curr Pain Headache Rep 10(2):126-129

11. van Vliet JA, Eekers PJ, Haan J, Ferrari MD, Dutch RUSSH Study Grou (2003) Features involved in the diagnostic delay of cluster headache. J Neurol Neurosurg Psychiatry 74(8):1123-1125

12. Bahra A, Goadsby PJ (2004) Diagnostic delays and mis-management in cluster headache. Acta Neurol Scand 109(3):175-179

13. Rozen TD, Fishman RS (2012) Female cluster headache in the United States of America: what are the gender differences? Results from the United States cluster headache survey. J Neurol Sci 317(1-2):17-28

14. The International Classification of Headache Disorders, 3rd edition (beta version). Cephalalgia. 2013:33(9):629-808. doi:10.1177/0333102413485658

15. Ferrari A, Zappaterra M, Righi F, Ciccarese M, Tiraferri I, Pini LA et al (2013) Impact of continuing or quitting smoking on episodic cluster headache: a pilot survey. J Headache Pain 14:48

16. Kudrow L (1976) Prevalence of migraine, peptic ulcer, coronary heart disease and hypertension in cluster headache. Headache 16(2):66-69

17. Lambru G, Castellini P, Manzoni GC, Torelli P (2010) Mode of occurrence of traumatic head injuries in male patients with cluster headache or migraine: is there a connection with lifestyle? Cephalalgia 30(12):1502-1508

18. Liang JF, Chen YT, Fuh JL, Li SY, Liu CJ, Chen TJ et al (2013) Cluster headache is associated with an increased risk of depression: a nationwide population-based cohort study. Cephalalgia 33(3):182-189

19. Pietrini U, De Luca M, De Santis G (2005) Hypertension in headache patients? A clinical study. Acta Neurol Scand 112(4):259-264

20. Robbins MS, Bronheim R, Lipton RB, Grosberg BM, Vollbracht S, Sheftell FD et al (2012) Depression and anxiety in episodic and chronic cluster headache: a pilot study. Headache 52(4):600-611

21. Rossi P, Allena M, Tassorelli C, Sances G, Di Lorenzo C, Faroni JV et al (2012) Illicit drug use in cluster headache patients and in the general population: a comparative cross-sectional survey. Cephalalgia 32(14):1031-1040

22. Rozen TD, Fishman RS (2012) Cluster headache in the United States of America: demographics, clinical characteristics, triggers, suicidality, and personal burden. Headache 52(1):99-113

23. Voiticovschi-losob C, Allena M, De Cillis I, Nappi G, Sjaastad O, Antonaci F (2014) Diagnostic and therapeutic errors in cluster headache: a hospital-based study. J Headache Pain 15:56

24. Xie Q, Huang Q, Wang J, Li N, Tan G, Zhou J (2013) Clinical features of cluster headache: an outpatient clinic study from China. Pain Med 14(6): 802-807 